\title{
全象限サンプリング法を用いたシミュレーションに基づく構造信頼性解析の研究
}

奥田 昇也 ${ }^{* 1}$ ，米澤 政昭*2

\section{A study of structural reliability analysis based on simulation using all quadrants sampling method}

\author{
Shoya OKUDA*1 and Masaaki YONEZAWA ${ }^{* 2}$ \\ ${ }^{* 1}$ Technical College, Kindai University \\ 7-1 Kasugaoka, Nabari-shi, Mie 518-0459, Japan \\ ${ }^{* 2}$ Department of Mechanical Engineering, Kindai University \\ 3-4-1 Kowakae, Higashiosaka-shi, Osaka 577-8502, Japan
}

Received: 11 June 2019; Revised: 8 October 2019; Accepted: 7 January 2020

\begin{abstract}
This study describes a simulation-based estimation procedure of the structural failure probability using an "all quadrants sampling method" newly proposed, in which a sample called as a real sample is generated in an arbitrary quadrant of the basic variable space and then the coordinates of the real sample point is transformed into those of pseudo sample points over all of other quadrants by applying the previously proposed "inter-quadrant relational expression." That is, once a real sample is generated in an arbitrary quadrant, and then pseudo samples are determined in all other quadrants concurrently. All of real and pseudo samples thus determined are used for the simulation to estimate structural failure probabilities. Numerical examples of various simulation methods combined with the proposed "all quadrants sampling method," that is, "all quadrant sampling Monte Carlo simulation," "all quadrant sampling directional simulation," etc. are presented showing that the proposed method is effective for shortening simulation time.
\end{abstract}

Keywords:Structural failure probability, Simulation based reliability analysis, Monte Carlo simulation, Directional simulation

\section{1. 緒 言}

本研究は, 基本確率変数空間全体をサンプリング対象領域として構造破損確率の推定を行う各種シミュレーシ ヨン法のサンプリングの効率化を図るために，ある象限に 1 個のサンプル（これを本研究では，実サンプルと呼 ぶ）を生成する度に，これに対応するサンプル（これを本研究では，疑似サンプルと呼ぶ）を基本確率変数空間 の全象限に変換して生成する「全象限サンプリング法」(奥田，米澤，2017)を適用した『全象限サンプリング・ シミュレーション法』を提案し，これに基づく構造破損確率の推定法に関して，その有効性を検討する.

提案手法では，象限間の相対的座標位置関係を与える「象限間関係式」(奥田，米澤，2017) を用いて，任意の 象限で実サンプル点を生成する度に，これに対応する疑似サンプル点を，実サンプル点の象限以外の他の全象限 に変換・生成を繰り返して, 実サンプルと疑似サンプルをすべて構造破損確率の推定に利用して, シミュレーシ ヨンのサンプリングの効率化を図る.

以下では，原始的モンテカルロ・シミュレーションに「全象限サンプリング法」を適用した『全象限サンプリ ング・モンテカルロ・シミュレーション法』，原始的モンテカルロ・シミュレーションに分散減少法の1つである 領域分割法(Harbitz, 1986)を利用したシミュレーション法 (これを本研究では, 領域分割シミュレーションと呼ぶ) に「全象限サンプリング法」を適用した『全象限サンプリング・領域分割シミュレーション法』, 方向シミュレー ション(Bjerager, 1988)に「全象限サンプリング法」を適用した『全象限サンプリング・方向シミュレーション法』 を提案し，これらの各種『全象限サンプリング・シミュレーション法』の有効性を検討する.

No.19-00242 [DOI:10.1299/transjsme.19-00242], J-STAGE Advance Publication date : 17 January, 2020

${ }^{* 1}$ 正員, 近畿大学工業高等専門学校（广518-0459 三重県名張市春日丘 7-1）

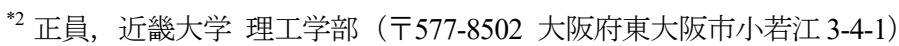

E-mail of corresponding author: okuda@ktc.ac.jp 


\section{2. 原始的モンテカルロ・シミュレーション}

構造システムの状態を表す限界状態関数を記述する基本確率変数 $\boldsymbol{u}=\left(u_{1}, u_{2}, \ldots, u_{k}\right)$ は, 標準直角座標系の $k$ 次 元正規確率変数で, 時間に依存しないものとする. 構造破損確率 $P_{f}$ は, 次式で与えられる(Freudenthal, 1956).

$$
P_{f}=\int_{\text {all } \boldsymbol{u}} \mathrm{I}_{D_{f}}(\boldsymbol{u}) f_{\boldsymbol{U}}(\boldsymbol{u}) d \boldsymbol{u}=E_{\boldsymbol{f}_{\boldsymbol{U}}}\left[\mathrm{I}_{D_{f}}(\mathbf{u})\right]
$$

ここで， $f_{\boldsymbol{U}}(\boldsymbol{u})$ は，基本確率変数 $\boldsymbol{u}$ の標準正規結合確率密度関数であり， $E_{f_{\boldsymbol{U}}}[\cdot]$ は, $[\cdot]$ の $f_{\boldsymbol{U}}(\boldsymbol{u})$ に関する期 待值を表す. $\mathrm{I}_{D_{f}}(\boldsymbol{u})$ は, 構造システムの状態を判別する指標関数であり, システムが破損状態にあれば, $\mathrm{I}_{D_{f}}(\boldsymbol{u})=1$, 安全状態にあれば, $\mathrm{I}_{D_{f}}(\boldsymbol{u})=0$ となる.

原始的モンテカルロ・シミュレーションに基づく構造破損確率 $P_{f}$ の推定量 $\hat{P}_{f}$ は， $f_{\boldsymbol{U}}(\boldsymbol{u})$ に従う $N$ 個のサン プル $\boldsymbol{u}^{(j)},(j=1,2, \ldots, N)$ を生成して, 次式によって与えられる.

$$
\begin{aligned}
& \hat{P}_{f}=\frac{1}{N} \sum_{j=1}^{N} P_{f}^{(j)} \\
& P_{f}^{(j)}=\mathrm{I}_{D_{f}}\left\lfloor\boldsymbol{u}^{(j)}\right\rfloor
\end{aligned}
$$

構造破損確率の推定量の分散 $\operatorname{Var}\left(\hat{P}_{f}\right)$ およびその変動係数 $\operatorname{Cov}$ は, 次式によって与えられる.

$$
\begin{aligned}
& \operatorname{Var}\left(\hat{P}_{f}\right)=\frac{1}{N(N-1)} \sum_{j=1}^{N}\left(P_{f}(j)-\hat{P}_{f}\right)^{2} \\
& \operatorname{Cov}=\sqrt{\operatorname{Var}\left(\hat{P}_{f}\right) / \hat{P}_{f}}
\end{aligned}
$$

\section{3. 領域分割シミュレーション}

分散減少手法の 1 つである領域分割法(Harbitz, 1986)を原始的モンテカルロ・シミュレーションに適用した領域 分割シミュレーションの概要を以下に示寸.

まず, 限界状態曲面上の設計点を決定し, 原点から設計点までの距離を $\beta$ として, 式(1)の構造破損確率の積分 領域を, $\beta$ を半径とする超球（ $\beta$ 超球という）の内外に分けると, $P_{f}$ は, 次式で与えられる.

$$
P_{f}=\int_{|\mathbf{u}| \leq \beta} \mathrm{I}_{D_{f}}(\boldsymbol{u}) f_{\boldsymbol{U}}(\boldsymbol{u}) d \boldsymbol{u}+\underset{|\boldsymbol{u}|>\beta}{\int} \mathrm{I}_{D_{f}}(\boldsymbol{u}) f_{\boldsymbol{U}}(\boldsymbol{u}) d \boldsymbol{u}
$$

式(6)の第 1 項は, 安全領域の積分であり, 零となるので, 構造破損確率推定に関しては, 第 2 項の $\beta$ 超球の外 部領域の積分のみを取り扱えばよい。

基本確率変数 $\boldsymbol{u}=\left(u_{1}, u_{2}, \ldots, u_{k}\right)$ は，動径 $r$ と方向ベクトル $\boldsymbol{a}=\left(a_{1}, a_{2}, \ldots, a_{k}\right)$ の積 $\boldsymbol{u}=r \boldsymbol{a}$ で表される.ここで, $a_{1}, a_{2}, \ldots, a_{k}$ は, $u_{1}, u_{2}, \ldots, u_{k}$ 軸に対する方向余弦である. さらに動径 $r$ と方向ベクトル $\boldsymbol{a}$ の結合確率密度関数を $f_{R \boldsymbol{A}}(r \boldsymbol{a})$ とすると, 構造破損確率は, 次のように表される.

$$
\begin{aligned}
& P_{f}=\int_{|u|>\beta} \mathrm{I}_{D_{f}}(\boldsymbol{u}) f_{\boldsymbol{U}}(\boldsymbol{u}) d \boldsymbol{u}=\int_{\boldsymbol{a} \in \Omega_{k} \beta} \int_{D_{f}}^{\infty} \mathrm{I}_{D_{f}}(r \boldsymbol{a}) r^{k-1} f_{R \boldsymbol{A}}(r \boldsymbol{a}) d r d \boldsymbol{a}=\int_{\boldsymbol{a} \in \Omega_{k}} P_{f}(\boldsymbol{a}) f_{\boldsymbol{A}}(\boldsymbol{a}) d \boldsymbol{a} \\
& P_{f}(\boldsymbol{a})=\int_{\beta}^{\infty} \mathrm{I}_{D_{f}}(r \boldsymbol{a}) f^{2} \chi^{2}\left(r^{2}\right) d r
\end{aligned}
$$

ここで, $f_{\chi^{2}}\left(r^{2}\right)$ は, 自由度 $k$ のカイ 2 乗確率密度関数であり, $\Omega_{k}$ は, $k$ 次元単位超球である. 
次に, $\beta$ 超球の外部領域で定義される変形カイ 2 乗確率密度関数 $f_{\chi_{t}^{2}}\left(r^{2}\right)$ を導入する. すなわち,

$$
f_{\chi_{t}^{2}}\left(r^{2}\right)=\left\{\begin{array}{cc}
f_{\chi^{2}}\left(r^{2}\right) /(1-P) & : r>\beta \\
0 & : r \leq \beta
\end{array}\right.
$$

ここで，Pは， $\beta$ 超球領域内の確率超体積であり，次式で決定される.

$$
P=\int_{r \leq \beta} f \chi^{2}\left(r^{2}\right) d r=F \chi^{2}\left(\beta^{2}\right)
$$

$F_{\chi^{2}}(\cdot)$ は, 自由度 $k$ のカイ 2 乗確率分布関数であり, 変形カイ 2 乗累積分布関数 $F \chi_{t}^{2}\left(r^{2}\right)$ は, 次式で与えられる.

$$
F_{\chi_{t}^{2}}\left(r^{2}\right)=\int_{\beta}^{r} f_{\chi_{t}^{2}}\left(r^{2}\right) d r
$$

式(7)に変形カイ 2 乗確率密度関数を導入すると, 構造破損確率 $P_{f}$ は次式で与えられる.

$$
P_{f}=\int_{\boldsymbol{a} \in \Omega_{k}} P_{f}(\boldsymbol{a}) f_{\boldsymbol{A}}(\boldsymbol{a}) d \boldsymbol{a}=(1-P) \int_{\boldsymbol{a} \in \Omega_{k}} \int_{\beta}^{\infty} \mathrm{I}_{D_{f}}(r \boldsymbol{a}) f_{\chi_{t}^{2}}\left(r^{2}\right) d r f_{\boldsymbol{A}}(\boldsymbol{a}) d \boldsymbol{a}=(1-P) E_{f} \chi_{\chi_{t}^{2}} f_{\boldsymbol{A}}\left[\mathrm{I}_{D_{f}}(r \boldsymbol{a})\right]
$$

ここで, $E_{f_{\chi_{t}^{2}} f_{\boldsymbol{A}}}[\cdot]$ は,$f_{\chi_{t}^{2} f_{\boldsymbol{A}}}$ に関する[・]の期待值である.

動径 $r$ のンプル生成は, まず, 変形カイ 2 乗確率分布の累積相対度数を構成する. すなわち, $\beta$ から $\beta+5$ の 範囲を分割幅 $\Delta r=0.01$ で, $N K$ 個に階級分けし，カイ 2 乗確率密度関数を分割幅の区間ごとに数值積分して確率 を計算し, これらに式(10)の $P$ を用いて $1 /(1-P)$ 倍した值を累積し, 式(11)の累積変形加イ2 乗確率分布の相対度 数とする. 次に一様乱数 $f^{(j)}$ と累積変形カイ 2 乗確率分布の相対度数から, 動径サンプル $r_{l}^{(j)},(l=1,2, \ldots, N K)$ を 決定する.この関係を図 1 に示寸(米澤，奥田，1993).

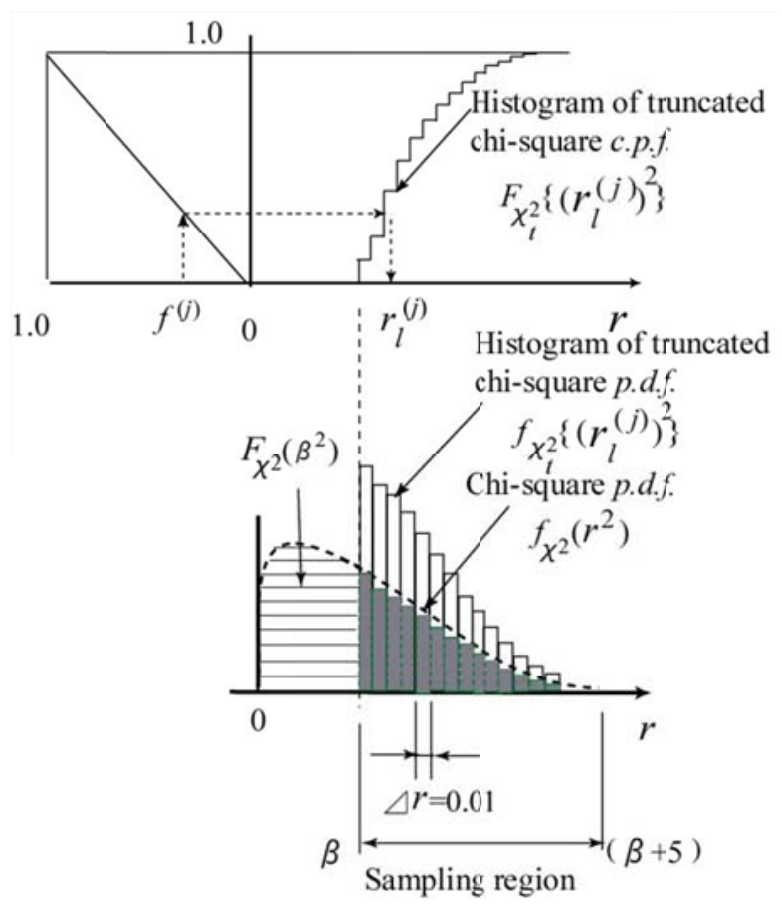

Fig. 1 A conceptual diagram of a radial sample generation based on the cumulative truncated chi-square relative frequency. 
次に, 基本確率変数 $\boldsymbol{u}=r \boldsymbol{a}$ のサンプル生成のために, 方向ベクトル $\boldsymbol{a}$ と動径 $r$ のサンプル生成について考える. 方向ベクトル $\boldsymbol{a}$ の $j$ 番目のサンプル $\boldsymbol{a}^{(j)}=\left(a_{1}, a_{2}, \ldots, a_{k}\right)^{(j)}$ は, $n$ 個の標準正規乱数のサンプル $v_{n}^{(j)},(n=1,2, \ldots, k)$ を用 いて，次のように生成される.

$$
\boldsymbol{a}^{(j)}=\left(v_{1}, v_{2}, \ldots, v_{k}\right) / \sqrt{\sum_{n=1}^{k}\left(v_{n}^{(j)}\right)^{2}}
$$

結局, 領域分割シミュレーションに基づく構造破損確率 $P_{f}$ の推定量 $\hat{P}_{f}$ とその変動係数 $\operatorname{Cov}$ は, 式(14)と式(2), (4)，(5)により決定される.

$$
P_{f}^{(j)}=(1-P) \mathrm{I}_{D_{f}}\left\lfloor\left(r_{l} \boldsymbol{a}\right)^{(j)}\right\rfloor
$$

\section{4. 全象限サンプリング · モンテカルロ・シミュレーション法}

標準直角座標系の $k$ 次元基本確率変数空間は, $q=2^{k}$ 個の象限で構成される.

本研究では, 第 1 象限, 第 2 象限, $\cdots$, 第 $q$ 象限を, $[1 \mathrm{st}]$ 象限, $[2 \mathrm{nd}]$ 象限, $\cdots,[q$-th $]$ 象限と, 表示寸る.

まず，原始的モンテカルロ・シミュレーションのサンプリングにおいて，例えば， [1st]象限 $(q=1) に$ 生成する 第 1 番目 $(j=1)$ の基本確率変数 $\boldsymbol{u}$ のサンプルを, 次のように表す.

$$
\boldsymbol{u}^{1(1)}=\left[u_{1}^{1(1)}, u_{2}^{1(1)}, \ldots, u_{n}^{1(1)}, \ldots, u_{k}^{1(1)}\right]
$$

ここで, $u_{n}^{1(1)}$ は, $[1 \mathrm{st}]$ 象限 $(q=1)$ の 1 番目 $(j=1)$ の $k$ 次元のサンプルベクトル $\boldsymbol{u}$ の $k$ 個の要素の中の $n$ 番目 $(1<n$ $<k)$ の要素を表す.

次に， $\boldsymbol{u}^{1(1)}$ を実サンプルとして，これを次式に示すように，[1st]象限以外の他の全象限における疑似サンプル $\boldsymbol{u}^{q(1)},\left(q=2,3, \ldots, 2^{k}\right)$ として変換・生成する(奥田，米澤，2017) .

$$
\begin{aligned}
\boldsymbol{u}^{q(1)} & =\left[u_{1}^{q(1)}, u_{2}^{q(1)}, \ldots, u_{n}^{q(1)}, \ldots, u_{k}^{q(1)}\right] \\
& =\left[(-1)^{\text {roundup }}\left(\frac{2^{0}+q}{2^{0}}\right) u_{1}^{1(1)},(-1)^{\text {roundup }}\left(\frac{2^{1}+q}{2^{1}}\right) u_{2}^{1(1)}, \ldots,(-1)^{\text {roundup }}\left(\frac{2^{n-1}+q}{2^{n-1}}\right) u_{n}^{1(1)}, \ldots,(-1)^{\text {roundup }}\left(\frac{2^{k-1}+q}{2^{k-1}}\right) u_{k}^{1(1)}\right]
\end{aligned}
$$

ここで, roundup ( )は, 切り上げ関数で, ( )内の小数点以下を切り上げて, 整数とする命令であり, プログラ ム言語 FORTRAN では, ceiling( )で表される.

シミュレーションで繰り返し生成される過程の第 $j$ 番目に $[1 \mathrm{st}]$ 象限 $(q=1)$ で生成される $k$ 次元の実サンプルベ クトル $\boldsymbol{u}^{1(j)}$ が, $[q-\mathrm{th}]$ 象限の $j$ 番目の疑似サンプルベクトルとして, 変換・生成される確率变数ベクトル $\boldsymbol{u}^{q(j)}$ の $n$ 番目の要素は，次式で表され，これが「象限間関係式」である.

$$
u_{n}^{q(j)}=(-1)^{\text {roundup }}\left(\frac{2^{n-1}+q}{2^{n-1}}\right) u_{n}^{1(j)}, \quad\left(q=2,3, \ldots, 2^{k}\right)
$$

このように実サンプルに対応寸る疑似サンプルを全象限に変換・生成する「全象限サンプリング法」と名付け， これを原始的モンテカルロ・シミュレーションに適用して，構造破損確率を推定する方法を『全象限サンプリン グ・モンテカルロ・シミュレーション法』とする．なお，式(17)は， $j$ 番目の実サンプルを[1st]象限で生成する場 合を示しているが, 一般的に, 実サンプルは, 必ずしも $[1 \mathrm{st}]$ 象限に限定して生成する必要はなく, 任意の象限で 生成することができる.

図 2 に，実サンプルとこれに対応して変換・生成される疑似サンプルの概念図を示す．図中の記号「○」は， $[1 \mathrm{st}]$ 象限において, 原始的モンテカルロ・シミュレーションによって, 生成された $j$ 番目および $(j+1)$ 番目の実サ 


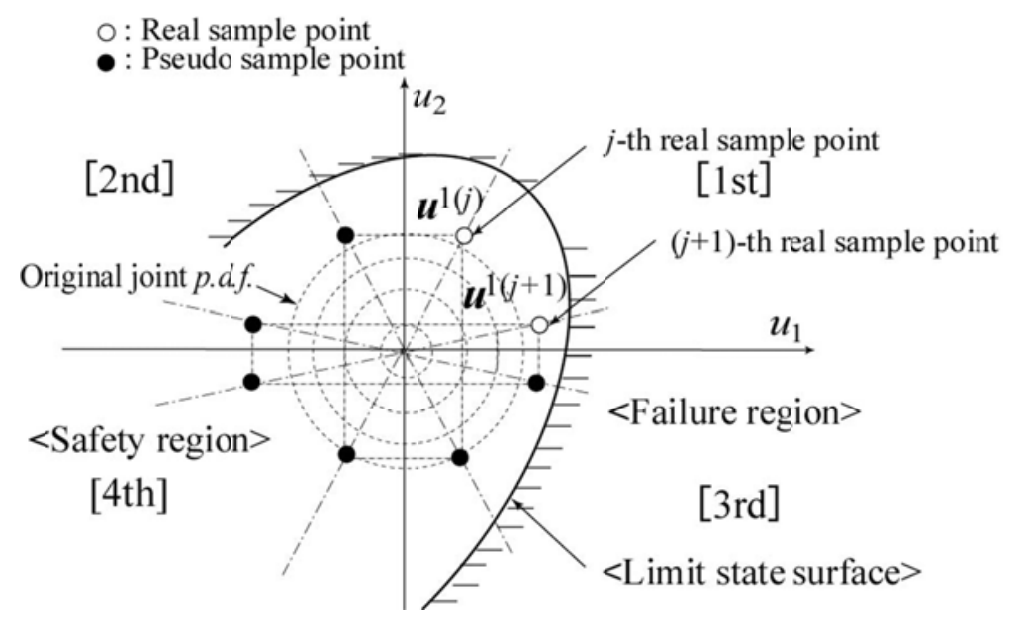

Fig. 2 A real sample point generated in the [1st] quadrant and pseudo sample points determined in all of other quadrants in the case of proposed all quadrant M. C. S. method.

ンプル点(Real sample point)を示し, 実サンプル点に対応して変換・生成される疑似サンプル点(Pseudo sample point) を記号「○」で示している. なお, 図 2 の象限表示[1st], [2nd], [3rd], [4th]は, 通常の象限表示と異なっている.

実サンプルの生成数を $N_{R}$ とすると，『全象限サンプリング・モンテカルロ・シミュレーション法』の総サンプ ル数 $N$ は, 実サンプル・疑似サンプルすべてを合わせて, $N=N_{R} \times 2^{k}$ であり, 構造破損確率の推定量および分散 は, 次式で与えられる.

$$
\begin{aligned}
& \hat{P}_{f}=\frac{1}{N} \sum_{j=1}^{N_{R}} \sum_{q=1}^{2^{k}} P_{f}^{q(j)} \\
& P_{f}^{q(j)}=\mathrm{I}_{D_{f}}\left[\boldsymbol{u}^{q(j)}\right] \\
& \operatorname{Var}\left(\hat{P}_{f}\right)=\frac{1}{N(N-1)} \sum_{j=1}^{N_{R}} \sum_{q=1}^{2^{k}}\left(P_{f}^{q(j)}-\hat{P}_{f}\right)^{2}
\end{aligned}
$$

\section{5. 全象限サンプリング · 領域分割シミュレーション法}

第 3 章で述べた領域分割シミュレーションに「全象限サンプリング法」を適用して，構造破損確率を推定する 『全象限サンプリング・領域分割シミュレーション法』について考える.

$N_{R}$ 個の実サンプルの $j$ 番目サンプルが，例えば，[1st]象限内で生成されるものとする．すなわち，実サンプル を $\boldsymbol{u}^{1(j)}=r_{l}^{(j)} \boldsymbol{a}^{1(j)}$ と表す. その実方向ベクトルサンプルを, $\boldsymbol{a}^{1(j)}=\left[a_{1}^{1(j)}, a_{2}^{1(j)}, \ldots, a_{n}^{1(j)}, \ldots, a_{k}^{1(j)}\right],\left(j=1,2, \ldots, N_{R}\right)$ と 表すと, 対応する $\left[q\right.$-th] 象限内に, 変換・生成される $j$ 番目の疑似方向ベクトルサンプル $\boldsymbol{a}^{q(j)},\left(q=2,3, \ldots, 2^{k}\right)$ は, 次式で決定される.

$$
\begin{aligned}
\boldsymbol{a}^{q(j)} & =\left[a_{1}^{q(j)}, a_{2}^{q(j)}, \ldots, a_{n}^{q(j)}, \ldots, a_{k}^{q(j)}\right] \\
& =\left[(-1)^{\text {roundup }}\left(\frac{2^{0}+q}{2^{0}}\right) a_{1}^{1(j)},(-1)^{\text {roundup }}\left(\frac{2^{1}+q}{2^{1}}\right) a_{2}^{1(j)}, \ldots,(-1)^{\text {roundup }}\left(\frac{2^{n-1}+q}{2^{n-1}}\right) a_{n}^{1(j)}, \ldots,(-1)^{\text {roundup }}\left(\frac{2^{k-1}+q}{2^{k-1}}\right) a_{k}^{1(j)}\right]
\end{aligned}
$$




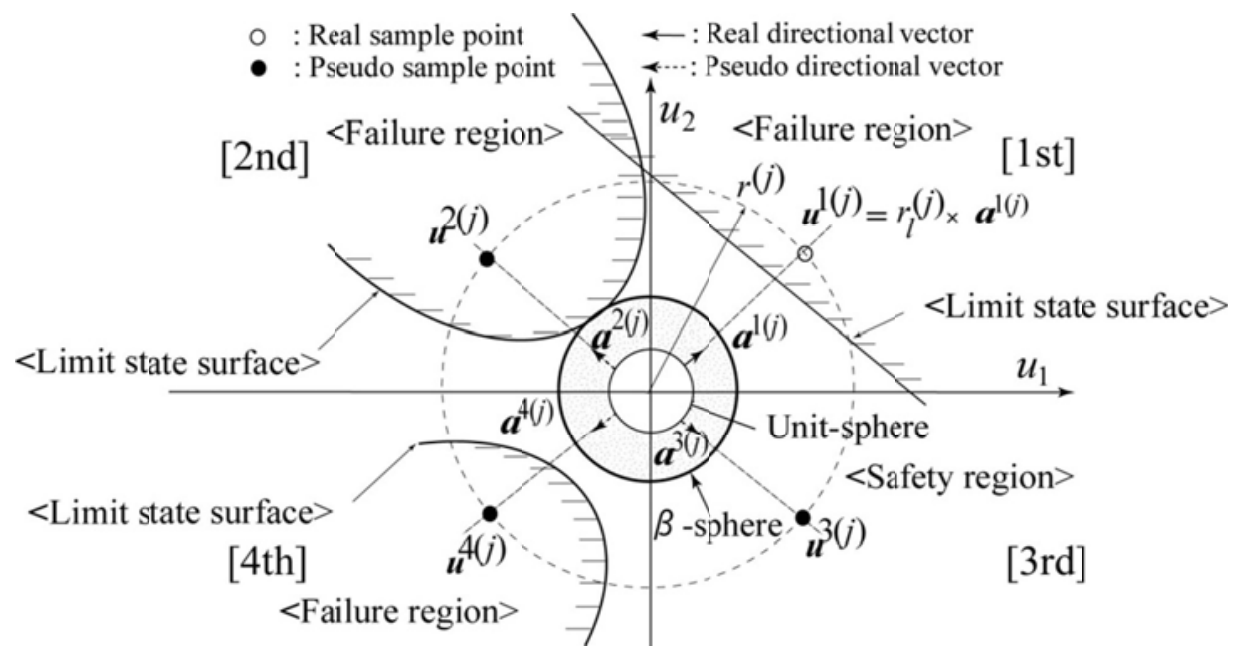

Fig. 3 A real sample point generated in the [1st] quadrant and pseudo sample points determined in all of other quadrants in the case of proposed all quadrant P. O. R. method.

$[1 \mathrm{st}]$ 象限内で生成した実サンプル点 $\boldsymbol{u}^{1(j)}=r_{l}^{(j)} \boldsymbol{a}^{1(j)}$ に対して, 式(21)を適用して, [2nd]象限, [3rd]象限, 一・ $\left[2^{k}\right.$-th $]$ 象限へと，疑似サンプル点に変換·生成する関係を図 3 に示寸.

構造破損確率の推定量 $\hat{P}_{f}$ は, 実サンプル数 $N_{R}$ の方向ベクトルサンプル $\boldsymbol{a}^{(j)},\left(j=1,2, \ldots, N_{R}\right)$ と, 各方向サン プルに対応する $2^{k}$ 個の全象限の疑似方向ベクトルサンプルから総サンプル数は $\left\{N=N_{R} \times 2^{k}\right\}$ となるので, 次式を 用いて, 構造破損確率の推定量 $\hat{P}_{f}$ は式(18), 推定量の分散 $\operatorname{Var}\left(\hat{P}_{f}\right)$ は式(20), 変動係数 $\operatorname{Cov}$ は式(5)により与えられ る.

$$
P_{f}^{q(j)}=(1-P) \mathbf{I}_{D_{f}}\left[\left(r_{l} \boldsymbol{a}\right)^{q(j)}\right]
$$

\section{6. 全象限サンプリング · 方向シミュレーション法}

「全象限サンプリング法」を適用した『全象限サンプリング・方向シミュレーション法』について考える. 方向シミュレーションに基づく構造信頼性解析において, 例えば, [1st]象限 $(q=1)$ において生成される, 第 $j$ 番 目の実方向ベクトルサンプル, $\boldsymbol{a}^{1(j)}=\left[a_{1}^{1(j)}, a_{2}^{1(j)}, \ldots, a_{n}^{1(j)} \ldots, a_{k}^{1(j)}\right],\left(j=1,2, \ldots, N_{R}\right)$ を生成してシミュレーション を実行する. 式(21)によって，疑似方向ベクトルサンプル $\boldsymbol{a}^{q(j)}=\left[a_{1}^{q(j)}, a_{2}^{q(j)}, \ldots, a_{n}^{q(j)} \ldots ., a_{k}^{q(j)}\right],\left(q=2,3, \ldots, 2^{k}\right)$ は, 変換・生成される. 次に, 原点から方向ベクトル $\boldsymbol{a}^{q(j)}$ 方向の直線と限界状態曲面との交点までの距離 $r_{\boldsymbol{a}}(j)$ を決定し，この方向の破損確率を次式で決定する.

$$
P_{f}^{q(j)}=1-F_{\chi^{2}}\left[\left(r_{\boldsymbol{a}^{q}}(j)\right)^{2}\right]
$$

式(23)を用いて, 構造破損確率の推定量 $\hat{P}_{f}$ と, 推定量の分散 $\operatorname{Var}\left(\hat{P}_{f}\right)$ は, 式(18), 式(20)により決定され，これら の結果を用いて，変動係数 Cov は，式(5)により決定される.

図 4 に，2 次元空間における実方向ベクトルサンプルに対応する疑似方向ベクトルサンプルの関係を示す. な お, 図中の半径 $r=10$ の一点鎖線の円は, 原点から限界状態曲面までの距離 $r=10$ を上限值と想定していること を表す. 寸なわち, $r>10$ の場合は, $P_{f}^{q(j)}=0$ として取り扱う. 


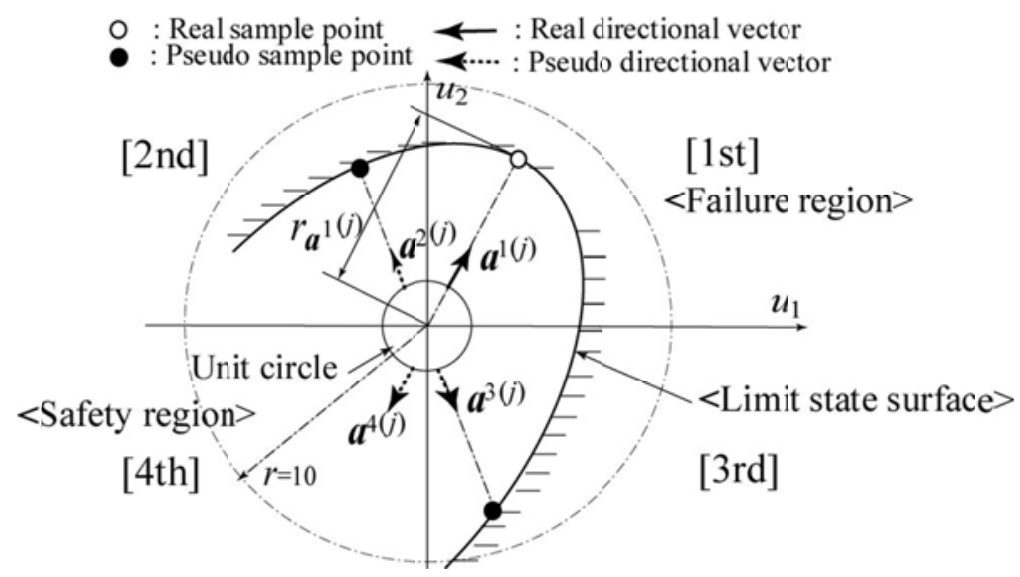

Fig. 4 A real sample point generated in the [1st] quadrant and pseudo sample points determined in all of other quadrants in the case of proposed all quadrant D. S. method.

\section{7. 数値計算例}

『全象限サンプリング・モンテカルロ・シミュレーション法』 (以下で, All quadrant M. C. S.と表す), 『全象限 サンプリング・方向シミュレーション法』(以下で, All quadrant D. S. と表す), 『全象限州ンプリング・領域分割シ ミュレーション法』(以下で, All quadrant P. O. R と表す), そして通常のシミュレーション法である原始的モンテ カルロ・シミュレーション(以下で，M.C.S.と表す), 方向シミュレーション (以下で，D. S.と表す), 領域分割シ ミュレーション(以下で, P. O.R.と表す)によって構造破損確率を推定し, 結果を比較して表に示す. なお, 「全象 限サンプリング法」は, 限界状態関数の基本確率変数の数が多くなると, 全象限の数が増加し, 計算処理時間が 飛躍的に増加する点を考慮して, 数值計算例の対象とした構造システムは, ここでは, 基本確率変数が 12 以下で 多破損モードを有する限界状態関数を持つ構造システムに限って検討を行った. また, 各限界状態関数の基本確 率変数は, 互いに独立で, 時間に依存しない正規確率分布に従うものとし, それらのサンプルの正規乱数は, Box Muller 法(Box and Muller, 1958) に基づいて生成した. また，P. O. R.の場合に必要な信頼性指標の最小值 $\beta_{\min }$ の決 定は, 「RF 法の初期点を全象限の限界状態曲面上に定める設計点探索法」(奥田, 米澤, 2018) と RF 法(Rackwitz and Fiessler, 1978) の 2 種類で，10回の繰り返しで行った. D. S. やAll quadrant D. S. において，原点から方向べクト ルの方向の直線の限界状態曲面との交点までの距離は, 「2 分法」(渡辺他, 1993) で決定し, その誤差は $10^{-4}$ 以下 となるようにした. 各手法による構造破損確率の推定量の変動係数 Cov が, Cov<0.01の条件が満たされたとき, シミュレーションを停止し，その時の所要サンプル数を Total samples $N$, 総計算時間を CPU time [sec]で示した. 従来の各種シミュレーション法と提案手法の各種『全象限サンプリング・シミュレーション法』との総計算時間 の短縮効果を比較するために，各種シミュレーション法の所要計算時間を基準として，シミュレーション時間の 短縮率: FSS(Fractional Shortening of simulation) として示した.

シミュレーションによる構造破損確率の推定量の精度を比較するために, サンプル数 $N=10^{11}$ の原始的モンテ カルロ・シミュレーションによる構造破損確率の推定量を, 厳密解 (以下で, Exact で表す) として示す. 使用計 算機・言語は，「富士通製 ESPRIMO (CORE i5 ) 64 bit マシン」・「インテル Visual Fortran」である.また，一様乱 数(Kahaner et al., 1988) の等確率性，系列相関および連の検定は，有意水準 $5 \%$ で棄却されないことを確認してい る.

\section{【Case 1】 2 層の門形ラーメン構造}

図 5 に示寸 2 層の門形ラーメン構造の構造破損確率推定問題を考える. 限界状態関数, 基本確率変数の統計デ 一タを表 1, 表 2 に示す (小野他, 1990). $M_{1}, M_{2}, \ldots, M_{8}$ は, 塑性モーメントで, $S_{1}, S_{2}, S_{3}, S_{4}$ は, 外部荷重である. なお, 領域分割シミュレーションにおいては, $\beta$ 超球の信頼性指標として, $\beta_{\min }=3.404$ とし, 半径 $\beta_{\min }$ の超球外 の確率は， $1-P=0.479$ となる. 


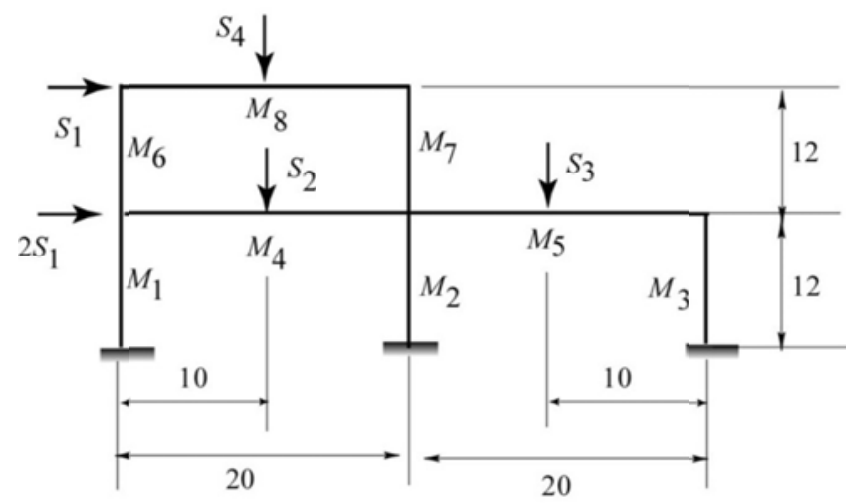

Fig. 5 A frame structure.

Table 1 Limit state functions for Case 1.

\begin{tabular}{c:l}
$\begin{array}{r}\text { Mode } \\
\text { no. }\end{array}$ & \multicolumn{1}{|c}{ Limit state function } \\
\hline 1 & $M_{1}+2 M_{2}+2 M_{3}+3 M_{4}+2 M_{6}+M_{7}+2 M_{8}-48 S_{1}-10 S_{2}-10 S_{4}$ \\
\hline 2 & $2 M_{1}+2 M_{2}+M_{3}-36 S_{1}$ \\
\hline 3 & $M_{1}+2 M_{2}+2 M_{3}+4 M_{4}+2 M_{5}+M_{6}+M_{7}+2 M_{8}-48 S_{1}-10 S_{2}-$ \\
\hline 4 & $10 S_{3}-10 S_{4}$ \\
\hline 5 & $M_{1}+2 M_{2}+2 M_{3}+3 M_{4}+M_{6}-36 S_{1}-10 S_{2}$ \\
\hline 6 & $M_{6}+M_{7}+2 M_{8}-10 S_{4}$ \\
\hline 7 & $M_{3}+3 M_{5}-10 S_{3}$ \\
\hline 8 & $M_{1}+2 M_{2}+2 M_{3}+3 M_{4}+M_{6}+4 M_{8}-48 S_{1}-10 S_{2}-10 S_{4}$ \\
\hline & $4 M_{4}-10 S_{2}$ \\
\hline
\end{tabular}

Table 2 Statistical data of basic random variables for Case 1.

\begin{tabular}{c|r|c}
\hline Variable & $\begin{array}{c}\text { Mean } \\
\text { value }\end{array}$ & $\begin{array}{c}\text { Sandard } \\
\text { deviation }\end{array}$ \\
\hline$M_{1}, M_{2}, M_{3}, M_{6}, M_{7}, M_{8}$ & 90.0 & 10.5 \\
\hline$M_{4}$ & 150.0 & 22.5 \\
\hline$M_{5}$ & 120.0 & 18.0 \\
\hline$S_{1}$ & 5.0 & 1.25 \\
\hline$S_{2}$ & 26.5 & 3.975 \\
\hline$S_{3}$ & 18.0 & 4.50 \\
\hline$S_{4}$ & 14.0 & 3.50 \\
\hline
\end{tabular}

Case 1 について, 各種『全象限サンプリング・シミュレーション法』に基づく構造破損確率の推定結果を表 3 に示す．各種『全象限サンプリング・シミュレーション法』は，いずれも，従来の各種シミュレーション法の場 合に比べて, 総計算時間 CPU time [sec]が短縮され, FSS に関しては，特に，『全象限サンプリング・方向シミュ レーション法』(All quadrant sampling D. S.)が，最も短縮効果が高く，効率的であることが判った.さらに，推定 量の㛜密解との比較においては, 従来の各種シミュレーション法の場合, 㛜密解との誤差は $0.16 \%$ $0.48 \%$ 範囲 で，一方，各種『全象限サンプリング・シミュレーション法』の場合， $0.48 \%$ 0.64\%であり，後者の方が，少し 誤差が大きいことが判った.

Table 3 Estimation results for Case 1.

\begin{tabular}{c|c|c|c|c|c}
\hline Method & $N_{R}$ & Total samples $N$ & $\hat{P}_{f} \times 10^{-4}$ & CPU time [sec] & FSS \\
\hline D. S. & - & $1,034,880$ & 6.24 & 1.52 & 1.0 \\
\hline All quadrant sampling D. S. & 191 & 780,082 & 6.20 & 0.742 & 0.488 \\
\hline M. C. S. & - & $16,031,803$ & 6.24 & 14.60 & 1.0 \\
\hline All quadrant sampling M. C. S. & 3,946 & $16,159,256$ & 6.19 & 7.44 & 0.509 \\
\hline P. O. R. & - & $7,934,774$ & 6.20 & 11.51 & 1.0 \\
\hline All quadrant sampling P. O. R. & 1,923 & $7,876,074$ & 6.19 & 8.12 & 0.705 \\
\hline
\end{tabular}

Exact: $P_{f}=6.23 \times 10^{-4}, \quad \operatorname{Cov}=1.264 \times 10^{-4}$. 


\section{【Case 2】非線形限界状態関数をもつ構造システム}

曲げモーメントが作用する鉄筋コンクリート単鉄筋長方形はり(長, 1996) の構造破損確率推定問題を考える. この構造システムの限界状態関数は, 次式で表される 9 個の基本確率変数から構成される非線形関数である. な お, 領域分割シミュレーションにおいては, $\beta$ 超球の信頼性指標は, $\beta_{\min }=4.317$ とし, 半径 $\beta_{\min }$ の超球外の確率 は, $1-P=2.846 \times 10^{-2}$ となる.

$$
g(\boldsymbol{x})=x_{1} x_{2}\left\{x_{3}-\frac{x_{1} x_{2}}{1.7 x_{4} x_{5}}\right\} x_{6}-\left(x_{7}+x_{8}\right) x_{9}
$$

基本確率変数空間は, $2^{k}=2^{9}=512$ 個の象限から構成されている. 各基本確率変数は, $x_{1}$ : 鉄筋の断面積, $x_{2}$ :鉄 筋の降伏点強度, $x_{3}$ : 有効高さ, $x_{4}$ : 断面の幅, $x_{5}$ : コンクリートの円柱供試体の強度, $x_{6}$ : 強度算定修正係数, $x_{7}$ : 死荷重曲げモーメント， $x_{8}$ : 活荷重曲げモーメント， $x_{9}$ : 曲げモーメント算定修正係数である. 各基本確率変数の 統計データを表 4 に示す.

Case 2 について，各種『全象限サンプリング・シミュレーション法』に基づく構造破損確率推定結果を表 5 に 示寸. 各種『全象限サンプリング・シミュレーション法』は, いずれも, 従来の各種シミュレーション法の場合 に比べて, 総計算時間 CPU time [sec] が短縮され，FSS に関しては，特に，『全象限サンプリング・モンテカル ロ・シミュレーション法』 (All quadrant sampling M. C. S.)が，最も短縮効果が高く，効率的であることが判った. さらに，推定量の厳密解との比較においては，従来の各種シミュレーション法の場合，厳密解との誤差は $0 \%$ $1.45 \%$ の範囲で，一方，各種『全象限サンプリング・シミュレーション法』の場合， $0 \%$ 2.91\%であり，後者の 方が，少し誤差が大きいことが判った.

Table 4 Statistical data for Case 2.

\begin{tabular}{c|c|c}
\hline Variable & Mean value & Standard deviation \\
\hline$x_{1}$ & 75.49 & 2.2647 \\
\hline$x_{2}$ & $3,300.0$ & 132.0 \\
\hline$x_{3}$ & 84.92 & 4.246 \\
\hline$x_{4}$ & 100.0 & 5.0 \\
\hline$x_{5}$ & 288.0 & 57.6 \\
\hline$x_{6}$ & 1.0 & 0.1 \\
\hline$x_{7}$ & $6,061,000.0$ & 303050.0 \\
\hline$x_{8}$ & $2,564,000.0$ & 897400.0 \\
\hline$x_{9}$ & 1.0 & 0.1 \\
\hline
\end{tabular}

Table 5 Estimation results for Case 2.

\begin{tabular}{c|c|c|c|c|c}
\hline Method & $N_{R}$ & Total samples $N$ & $\hat{P}_{f \times 10^{-5}}$ & CPU time [sec] & FSS \\
\hline D. S. & - & $2,474,119$ & 1.39 & 18.64 & 1.0 \\
\hline All quadrant sampling D. S. & 4,974 & $2,546,504$ & 1.39 & 12.65 & 0.678 \\
\hline M. C. S. & - & $731,560,307$ & 1.37 & 1022.74 & 1.0 \\
\hline All quadrant sampling M. C. S. & $1,578,387$ & $808,134,042$ & 1.33 & 271.15 & 0.265 \\
\hline P. O. R. & - & $22,025,261$ & 1.35 & 22.74 & 1.0 \\
\hline All quadrant sampling P. O. R. & 622,483 & $21,817,280$ & 1.37 & 18.71 & 0.822 \\
\hline
\end{tabular}

Exact: $P_{f}=1.370 \times 10^{-5}, \quad \operatorname{Cov}=2.661 \times 10^{-3}$. 


\section{【Case 3】多破損・非線形限界状態関数をもつ構造システム}

図 6 に示寸等分布荷重が作用している梁・ケーブルの構造システムを考える (Ang and Tang, 1988). 破損モー ドを図 7 に示す.

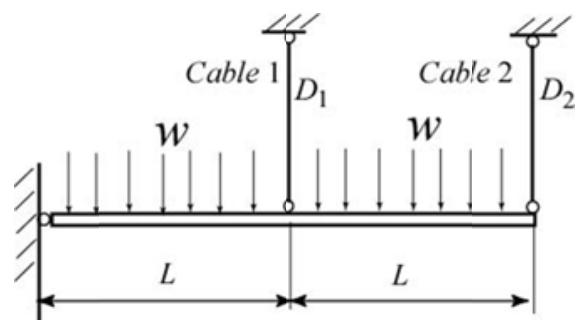

Fig. 6 Beam and cable system.

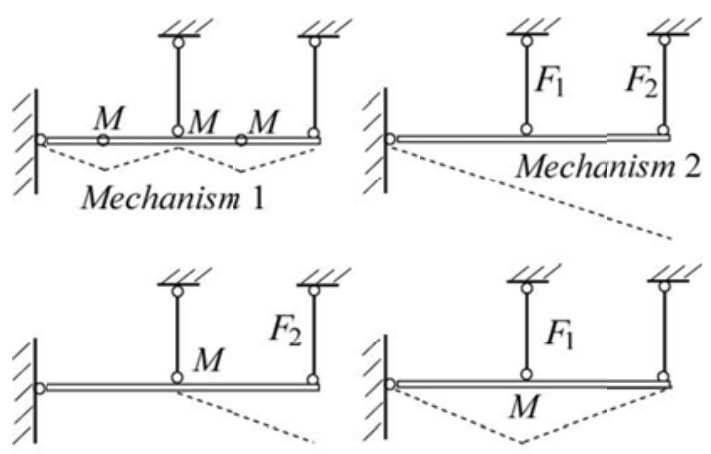

Mechanism 3
Mechanism 4

Fig. 7 Failure modes for Case 3.

各破損モードの限界状態関数を表 6 に, 各変数の統計データを表 7 に示す. 領域分割シミュレーションにお いては, $\beta$ 超球の信頼性指標は, $\beta_{\min }=2.930$ とし, 半径 $\beta_{\min }$ の超球外の確率は, $1-P=0.198$ となる. また，ケー ブルに作用する $F_{1}, F_{2}$ は， $F_{1}=$ 降伏応力 $(f) \times$ 断面積 $\left(D_{1}\right), F_{2}=$ 降伏応力 $(f) \times$ 断面積 $\left(D_{2}\right)$ で, $M$ は, 塑性モーメ ントである.

Case 3 について, 各種『全象限サンプリング・シミュレーション法』に基づく構造破損確率推定結果を表 8 に示す. 各種『全象限サンプリング・シミュレーション法』は, いずれも, 従来の各種シミュレーション法の場 合に比べて，総計算時間 CPU time [sec]を短縮され，FSS に関しては，特に，『全象限サンプリング・モンテカル ロ・シミュレーション法』(All quadrant sampling M. C. S.)が，最も短縮効果が高く，効率的であることが判った. さらに, 推定量の豲密解との比較においては, 従来の各種シミュレーション法の場合, 厳密解との誤差は $0.39 \%$ ～2.74\%の範囲で，一方，各種『全象限サンプリング・シミュレーション法』の場合， $1.56 \%$ 3.13\%であり， この場合でも後者の方が，少し誤差が大きいことが判った.

Table 6 Limit state functions for Case 3.

\begin{tabular}{c|l}
\hline Mode no. & Limit state function \\
\hline 1 & $6 M-w L^{2} / 2$ \\
\hline 2 & $F_{1} L+2 F_{2} L-2 w L^{2}$ \\
\hline 3 & $M+F_{2} L-0.5 w L^{2}$ \\
\hline 4 & $2 M+F_{1} L-w L^{2}$ \\
\hline
\end{tabular}

Note : $F_{1}=f \times D_{1}, F_{2}=f \times D_{2}$.
Table 7 Statistical data for Case 3.

\begin{tabular}{c|c|c}
\hline Variable & Mean value & Standard deviation \\
\hline$M$ & $13.8 \times 10^{5}$ & $2.07 \times 10^{5}$ \\
\hline$w$ & 30.0 & 6.0 \\
\hline$L$ & 488.0 & 2.44 \\
\hline$f$ & 4200.0 & 420.0 \\
\hline$D_{1}$ & 6.4 & 0.32 \\
\hline$D_{2}$ & 3.2 & 0.16 \\
\hline
\end{tabular}

Table 8 Estimation results for Case 3.

\begin{tabular}{c|c|c|c|c|c}
\hline Method & $N_{R}$ & Total samples $N$ & $\hat{P}_{f} \times 10^{-3}$ & CPU time [sec] & FSS \\
\hline D. S. & & 217,904 & 2.56 & 0.70 & 1.0 \\
\hline All quadrant sampling D. S. & 3,384 & 216,513 & 2.59 & 0.63 & 0.88 \\
\hline M. C. S. & & $3,871,273$ & 2.57 & 1.72 & 1.0 \\
\hline All quadrant sampling M. C. S. & 63,156 & $4,041,926$ & 2.47 & 0.88 & 0.51 \\
\hline P. O. R. & & 800,332 & 2.48 & 0.46 & 1.0 \\
\hline All quadrant sampling P. O. R. & 12,301 & 787,208 & 2.50 & 0.25 & 0.54 \\
\hline
\end{tabular}

Exact: $P_{f}=2.55 \times 10^{-3}, \quad C o v=6.24 \times 10^{-5}$. 


\section{8. 結 言}

本研究では, 新しいシミュレーション法として「全象限サンプリング法」を提案し, 従来の各種シミュレーシ ヨン法に「全象限サンプリング法」を適用した『全象限サンプリング・モンテカルロ・シミュレーション法』、『全 象限サンプリング・方向シミュレーション法』, 『全象限サンプリング・領域分割シミュレーション法』に基づく 構造破損確率推定法を提案し，数值計算例でその有効性を検討した.

1.「全象限サンプリング法」の手順によって, 少ない実サンプル生成で, シミュレーション過程で実際に利用で きる総サンプル数を増大させることができることを示した.

2. 各種「全象限サンプリング・シミュレーション法」に基づく構造破損確率の推定結果は, 従来の各種シミュレ ーション法による結果と比べて, 誤差は相対的に少し大きいが, 精度的には大差はなく, シミュレーションの 所要計算時間の短縮・効率化を図ることができることが判った.

3. 各種シミュレーション法, 計算対象とする構造システムの破損モード, 限界状態関数の形状, 線形・非線形性 の違いにより, 構造破損確率の推定量の結果や, シミュレーションの所要計算時間の短縮・効率化に差は生じ るが，『全象限サンプリング・モンテカルロ・シミュレーション法』による場合が，所要計算時間の短縮効果 が最も高いことが判った。

4. 本研究では, シミュレーションの停止条件を $\mathrm{Cov} \leq 0.01$ としたが，これをさらに，小さく設定する場合，構造 破損確率の推定量の精度は，もう少し改善されると考えられる. また限界状態関数の形状や確率変数の個数や 破損モード数の違う対象構造システムに対して, 各種『全象限サンプリング・シミュレーション法』を適用す る場合と従来の各種シミュレーション法による場合の結果にどのように影響するか等, 今後さらに, 別の対象 構造システムの問題について, 提案手法の有効性を検討する必要がある.

\section{文献}

Ang, A. H-S. and Tang, W. H. (共著)，伊藤學，亀田弘行，黒田勝彦，藤野陽三(共訳)，土木・建築のための確率・統 計の応用，丸善 (1988), pp. 528-529.

Bjerager, P., Probability integration by directional simulation, Journal of Engineering Mechanics, Vol. 114, No. 8 (1988), pp. 1285-1302.

Box, G. E. P. and Muller, M. E., A note on the generation of random normal deviates, The Annals of Mathematical Statistics, Vol. 29 (1958), pp. 610-611.

長尚，基礎知識としての構造信頼性設計(改訂新版)，山海堂(1996),pp. 103-104.

Freudenthal, A. M., Safety and the probability of structural failure, Transactions of the American Society of Civil Engineers, Vol. 121 (1956), pp. 1337-1375.

Harbitz, A., An efficient sampling method for probability of failure calculation, Structural Safety, Vol.3, Issue 2 (1986), pp. 109-115.

Kahaner, D., Meulert, C. and Nash, S., Numerical Methods and Software, Prentice Hall (1988), pp. 385-412.

奥田昇也，米澤政昭，全象限サンプリング・シミュレーション法に基づく構造信頼性解析法の研究，日本機械学 会 2017 関西支部研究発表会論文集, 174-1 (2017), pp. 101-104.

奥田昇也, 米澤政昭, RF 法による設計点探索のための全象限初期点設定法の研究(多峰性重点サンプリング・シ ミュレーションに基づく構造信頼性解析の効率化)，日本機械学会論文集，Vol. 84，No. 857 (2018)，DOI: 10.1299/transjsme. 17-00172.

小野徹郎，井戸田秀樹，戸塚明宏，高次積率標準化手法を用いた構造系の信頼性評価法，日本建築学会構造系論 文報告集, Vol. 418 (1990), pp. 71-79.

Rackwitz, R. and Fiessler, B., Structural reliability under combined random load sequences, Computers \& Structures, Vol. 9 (1978), pp. 489-494.

渡辺力，名取亮，小国力監修，Fortran77による数值計算ソフト（第3 刷)，丸善 (1993), pp. 143-147.

米澤政昭, 奥田昇也, 領域分割シミュレーション法による構造システムの信頼性解析, シミュレーション, Vol. 12, No.4 (1993), pp. 335-341. 


\section{References}

Ang, A. H-S. and Tang, W. H., (translated into Japanese by Itou, M., Kameda, H., Kuroda, K. and Fujino, Y.), Probability concepts in engineering planning and design, Volume II, Decision, Risk and Reliability, Maruzen (1988), pp. 528-529 (in Japanese).

Bjerager, P., Probability integration by directional simulation, Journal of Engineering Mechanics, Vol. 114, No. 8 (1988), pp. 1285-1302.

Box, G. E. P. and Muller, M. E., A note on the generation of random normal deviates, The Annals of Mathematical Statistics, Vol. 29 (1958), pp. 610-611.

Cho, T., Structural Reliability Design as Basic Knowledge (Newly revised version), Sankaido (1996), pp. 103-104 (in Japanese).

Freudenthal, A. M., Safety and the probability of structural failure, Transactions of the American Society of Civil Engineers, Vol. 121 (1956), pp. 1337-1375.

Harbitz, A., An efficient sampling method for probability of failure calculation, Structural Safety, Vol.3, Issue 2 (1986), pp. 109-115.

Kahaner, D., Meulert, C. and Nash, S., Numerical Methods and Software, Prentice Hall (1988), pp. 385-412.

Okuda, S. and Yonezawa, M., A study of structural reliability analysis based on all quadrants sampling simulation method, Transactions of the Japan Society of Mechanical Engineers Kansai Branch Conference, 174-1(2017), pp.101-104 (in Japanese).

Okuda, S. and Yonezawa, M., A study of all quadrants initial points setting method for design points search using RF algorithm (An efficient method of structural reliability analysis based on a multiple importance sampling simulation), Transactions of the JSME(in Japanese), Vol. 84, No. 857 (2018), DOI: 10.1299/transjsme. 17-00172.

Ono, T., Idota, H. and Totsuka, A., Reliability evaluation of structural systems using higher-order moment standardization technique (A study on reliability-based design using higher-order moment, part 3), Journal of Structural and Construction Engineering (Transactions of Architectural Institute of Japan), Vol. 418 (1990), pp. $71-79$ (in Japanese).

Rackwitz, R. and Fiessler, B., Structural reliability under combined random load sequences, Computers \& Structures, Vol. 9 (1978), pp. 489-494.

Watanabe, T., Natori, M. and Oguni, T., Numerical calculation software by Fortran77 (The third print), Maruzen (1993), pp. 143-147 (in Japanese).

Yonezawa, M. and Okuda, S., Structural reliability analysis based on simulation method with partition of the region technique, Japan Society for Simulation Technology, Vol. 12, No.4 (1993), pp. 335-341 (in Japanese). 